\title{
Effects of Cobalt and Nickel Substitution on Physical Properties of Perovskite Type Oxides Prepared by the Sol-Gel Citrate Method
}

\author{
R.Z. YARBAY ${ }^{a, b, *}$, H.E. Figen ${ }^{a}$ AND S.Z. BAYKARA ${ }^{a}$ \\ ${ }^{a}$ Chem. Eng. Dept., Yildiz Technical University, İstanbul, Turkey \\ ${ }^{b}$ Chem. and Process Eng. Dept., Bilecik University, Bilecik, Turkey
}

\begin{abstract}
In this study, lanthanum and Co-, Ni-based oxides at different compositions were prepared by the sol-gel citrate method. Ammonium carbonate and citric acid were used as complexing agent and solvent. The oxides were characterized by scanning electron microscopy-energy-dispersive spectroscopy, X-ray diffraction, and the Brunauer-Emmett-Teller method. Surface area analysis was carried out and the effects of substitution of cobalt and nickel on the physical properties of the synthesized oxides were investigated.
\end{abstract}

PACS: $81.20 . \mathrm{Fw}, 81.70 . \mathrm{Jb}, 81.16 . \mathrm{Be}$

\section{Introduction}

There is a growing interest in perovskite-type oxides with the general formula $\mathrm{ABO}_{3}$, where $\mathrm{A}$ is lanthanum and $\mathrm{B}$ is a first-row transition metal $(\mathrm{Cr}, \mathrm{Mn}, \mathrm{Fe}, \mathrm{Ni}$, or $\mathrm{Co}$ ) for use as catalysts or catalyst precursors for internal reforming of methane in solid oxide fuel cell systems and for $\mathrm{CO}_{2}$ reforming of $\mathrm{CH}_{4}$. As catalysts, the $\mathrm{B}$-site cation is considered to be responsible for the catalytic activity while the A-site cation is considered to be responsible for thermal stability [1].

Many metals are stable in the $\mathrm{ABO}_{3}$ perovskite structure provided that the $\mathrm{A}$ (in 12 coordination) and $\mathrm{B}$ (in octahedral symmetry) cations have dimensions $\left(r_{\mathrm{A}}>\right.$ $\left.0.90 \AA, r_{\mathrm{B}}>0.51 \AA\right)$ that are in agreement with the limits of the so-called "tolerance factor" $t(0.8<t<1.0)$ defined by Goldschmidt, as $t=\left(r_{\mathrm{A}}+r_{\mathrm{O}}\right) / \sqrt{2}\left(r_{\mathrm{B}}+r_{\mathrm{O}}\right)$, where $r_{\mathrm{A}}, r_{\mathrm{B}}$ and $r_{\mathrm{O}}$ are the ionic radii for $\mathrm{A}, \mathrm{B}$ and $\mathrm{O}$, respectively [2]. Both the $\mathrm{A}$-site and $\mathrm{B}$-site cations can be partially substituted with different cations, $\mathrm{A}^{\prime}$ and $\mathrm{B}^{\prime}$ $\left(\mathrm{A}_{1-x} \mathrm{~A}_{x}^{\prime} \mathrm{B}_{1-y} \mathrm{~B}_{y}^{\prime} \mathrm{O}_{3 \pm d}\right)$, to improve the structural stability of the perovskite and to introduce structural and electronic defects. Partial substitution of the A-site cation, where the valence of the $\mathrm{A}^{\prime}$ is different from that of $\mathrm{A}$ ion, has been shown to influence the catalytic activity by stabilizing the B-site cation in unusual oxidation states and by introducing structural defects, such as oxygen vacancies [1].

Regardless of the intrinsic properties and the final use of a given perovskite composition, the synthesis of a pow-

\footnotetext{
* corresponding author
}

der with well defined physical characteristics is the first important step in its successful application. Method of synthesis may greatly influence the physical characteristics of the powder and the performance of the material whether used directly as catalyst, or subsequently processed into sintered forms [3].

The preparation procedure is of fundamental importance to determine both activity and durability [4]. The preparation method is important in defining suitable textural characteristics and in achieving phases of great purity. Several techniques have been developed to address the problem of perovskite purity; the most commonly used of these is the sol-gel citrate (SGC) method. The complexing agent used in sol-gel citrate is citric acid. This method makes it possible to obtain high surface area, but it has the drawback of rather rapid sintering depending on the temperature [5].

In this paper the SGC method and its influence on some physical characteristics are described. The work was carried out with the goal of developing an efficient process for perovskite powder production.

\section{Experimental}

\subsection{Preparation}

$\mathrm{LaNi}_{1-x} \mathrm{Co}_{x} \mathrm{O}_{3}(x=0,0.2,0.5,0.8,1)$ perovskites were prepared by the sol-gel citrate method. $\mathrm{La}\left(\mathrm{NO}_{3}\right)_{3} \cdot 6 \mathrm{H}_{2} \mathrm{O}$ (ABCR), $\mathrm{Ni}\left(\mathrm{NO}_{3}\right)_{2} \cdot 6 \mathrm{H}_{2} \mathrm{O}$ (Carlo Erba), $\mathrm{Co}\left(\mathrm{NO}_{3}\right)_{3} \cdot 6 \mathrm{H}_{2} \mathrm{O}$ (Carlo Erba), citric acid monohydrate $\mathrm{C}_{6} \mathrm{H}_{8} \mathrm{O}_{7}$ (Carlo Erba) and ammonium carbonate (Carlo Erba) were used as reagents. In SGC method, hydrate nitrates were chosen as the metal precursors; not only because they are fundamental for the method, the $\mathrm{NO}_{3}^{-}$groups being the 
oxidizing agents, but also because their high solubility in water allows a proper homogenization [6].

An aqueous solution of citric acid was prepared. The aqueous solutions of metal nitrates were added to that of citric acid, and they were agitated for $1 \mathrm{~h}$. Then ammonium carbonate was added until the $\mathrm{pH}$ was 6 . The resulting solution was concentrated by slowly evaporating water under vacuum in a rotary evaporator at $75^{\circ} \mathrm{C}$ until a gel was obtained. This gel was dried in an oven, slowly increasing the temperature to $120^{\circ} \mathrm{C}$ and maintaining this temperature overnight, to produce a solid amorphous citrate precursor. The resulting precursor was milled, kept at $200^{\circ} \mathrm{C}$ and then calcined in air at $800^{\circ} \mathrm{C}$ for $5 \mathrm{~h}$ [7].

\subsection{Characterization}

Synthesized materials were characterized by scanning electron microscopy (SEM), X-ray diffraction (XRD) and the Brunauer-Emmett-Teller method measurements. In order to determine the morphology of the oxides, scanning electron microscopy-energy-dispersive spectrometry
(SEM-EDS) measurements were carried out on a CamScan Apollo 300 FEG-SEM equipment. XRD patterns of oxides were obtained with a Philips X'pert Pro XRD using $\mathrm{Cu} K_{\alpha}$ radiation. Identification of crystalline phases was carried out by comparison with the JCPDS standards. Adsorption-desorption isotherms were measured by using a Quantachrome Autosorb-1C by adsorption of $\mathrm{N}_{2}$. Surface areas were calculated according to BET method.

\section{Results and discussion}

\subsection{BET and XRD}

As shown in Table I, the BET surface areas of the serial $\mathrm{LaNi}_{1-x} \mathrm{Co}_{x} \mathrm{O}_{3}$ oxides fall in the range of $3.61-5.66 \mathrm{~m}^{2} / \mathrm{g}$. It is apparent that the elements at B-sites (i.e. Co vs. Ni in the present case) have an effect on the surface area of the perovskite oxides. The surface area is found to vary with increasing extent of Co-substitution, exhibiting a maximum at $x=0.5$. The perovskite structure can be retained up to a substitution level of $x=0.5$.

BET surface areas of $\mathrm{LaNi}_{1-x} \mathrm{Co}_{x} \mathrm{O}_{3}$.

TABLE I

\begin{tabular}{c|c|c|c|c|c}
\hline \hline \multirow{2}{*}{ Sample code } & \multicolumn{4}{|c}{$\mathrm{LaNi}_{1-x} \mathrm{Co}_{x} \mathrm{O}_{3}$} \\
\cline { 2 - 6 } & $\begin{array}{c}\mathrm{K} 010 \\
(x=0)\end{array}$ & $\begin{array}{c}\mathrm{K} 020 \\
(x=0.2)\end{array}$ & $\begin{array}{c}\mathrm{K} 002 \\
(x=0.5)\end{array}$ & $\begin{array}{c}\mathrm{K} 021 \\
(x=0.8)\end{array}$ & $\begin{array}{c}\mathrm{K} 001 \\
(x=1)\end{array}$ \\
\hline total surface area $\left(\mathrm{TSA}, \mathrm{m}^{2} / \mathrm{g}\right)$ & 3.61 & 4.4 & 5.66 & 4.757 & 4.03
\end{tabular}

Comparison of metal atomic ratios in oxides.

TABLE II

\begin{tabular}{c|c|c|c|c|c}
\hline \hline \multirow{2}{*}{ Sample code } & \multicolumn{2}{|c|}{ Atomic La/Ni } & \multicolumn{2}{|c|}{ Atomic La/Co } & \multirow{2}{*}{ TSA $\left[\mathrm{m}^{2} / \mathrm{g}\right]$} \\
\cline { 2 - 5 } & Theoretical & EDS & Theoretical & EDS & \\
\hline K010 & 1 & 1.03 & - & - & 3.61 \\
K020 & 1.25 & 1.69 & 5 & 6.93 & 4.4 \\
K002 & 2 & 2.19 & 2 & 2.21 & 5.66 \\
K021 & 5 & 4.87 & 1.25 & 1.78 & 4.757 \\
K001 & - & - & 1 & 1.07 & 4.03
\end{tabular}

The XRD pattern of the calcinated oxides is shown in Fig. 1 and indicates that the material is crystalline. The $d$-spacing values of oxides match well with the standard XRD pattern of $\mathrm{LaNiO}_{3}$ (JCPDS file no. 01-088-0633) and $\mathrm{LaCoO}_{3}$ (JCPDS file no. 01-084-0848), and hence confirm the formation of $\mathrm{LaNiO}_{3}$ and $\mathrm{LaCoO}_{3}$. This belongs to a rhombohedral crystal system. The diffractograms of the substituted perovskites show nearly the same perovskite peak as $\mathrm{LaNiO}_{3}$, although a slight shift to higher values of $\theta$ Bragg angles are detected. A decrease in the diffraction line intensity with increasing amount of cobalt is also observed with the exception of $\mathrm{LaCoO}_{3}$. At higher $\mathrm{Ni}$ and Co substitutions, an increase in the diffraction line intensity is obtained. In every case, phases different from perovskite phase are found.

\subsection{Surface Morphology of Oxides}

Magnification used in SEM analysis of K001, K002, K010 and K020 was $1000 \times$, and $2000 \times$ was used for K021. Surface morphology analysis of the synthesized $\mathrm{LaNi}_{1-x} \mathrm{Co}_{x} \mathrm{O}_{3}$ oxides reveal a wide range of particle sizes (Fig. 2); the smaller particles join together to form larger particles. The SEM images show the presence of small as well as large sized flake-like particles. Samples K021 and K002 with higher Ni and Co substitutions show large clusters as well as smaller ones, while the rest of the ox- 


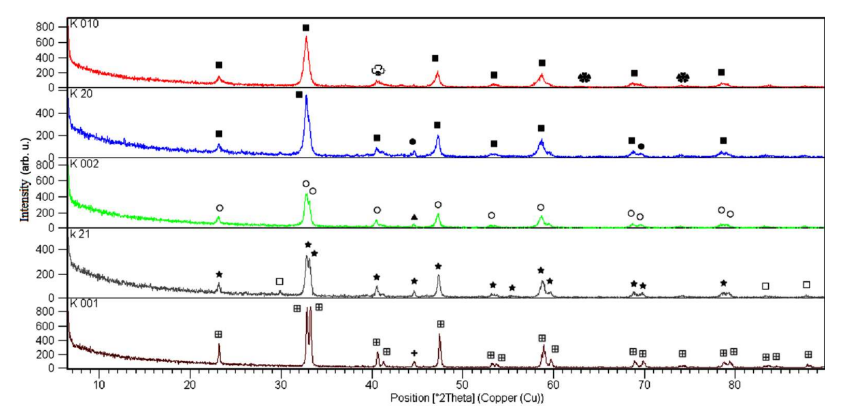

Fig. 1. XRD spectra: (匹) $\mathrm{LaNiO}_{3}$, (§) $\mathrm{LaNiO}_{2.7}$, (*) $\mathrm{La}_{3} \mathrm{Ni}_{2} \mathrm{O}_{7},(\bullet) \mathrm{LaNi}_{0.9} \mathrm{Co}_{0.1} \mathrm{O}_{2.54}$, (०) $\mathrm{LaNi}_{0.6} \mathrm{Co}_{0.4} \mathrm{O}_{3}$, (ム) $\mathrm{NiCo}_{2} \mathrm{O}_{4}, \quad(\star) \quad \mathrm{La}_{3} \mathrm{Co}_{3} \mathrm{O}_{8}, \quad(\square) \mathrm{LaNi}_{0.9} \mathrm{Co}_{0.1} \mathrm{O}_{2.54}$, $(\boxplus) \mathrm{LaCoO}_{3},(+) \mathrm{Co}_{3} \mathrm{O}_{4}$.

ides show more homogeneous distributions. The oxides with bigger particles also have larger surface area as indicated by BET results.

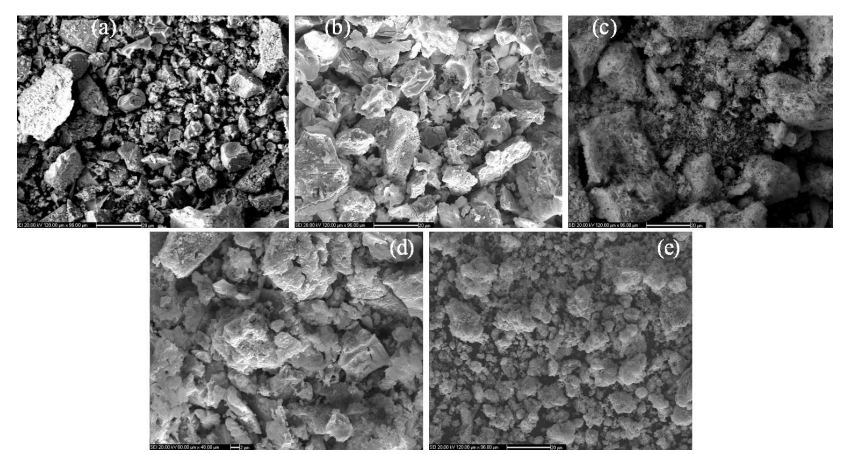

Fig. 2. SEM images of perovskite oxides: (a) K010, (b) K020, (c) K002, (d) K021, (e) K001.

According to SEM-EDS elemental analysis results, the atomic ratios of $\mathrm{La} / \mathrm{Ni}$ and $\mathrm{La} / \mathrm{Co}$ in the oxides are shown in Table II. The nominal compositions of the oxides prepared from precursor salts and the EDS test results of actual oxides are seen to be in good and acceptable agreement.

\section{Conclusion}

$\mathrm{LaNi}_{1-x} \mathrm{Co}_{x} \mathrm{O}_{3}$ perovskite-type oxides have been successfully synthesized by the sol-gel citrate method employing $\mathrm{La}\left(\mathrm{NO}_{3}\right)_{3} \cdot 6 \mathrm{H}_{2} \mathrm{O}, \mathrm{Ni}\left(\mathrm{NO}_{3}\right)_{2} \cdot 6 \mathrm{H}_{2} \mathrm{O}$, $\mathrm{Co}\left(\mathrm{NO}_{3}\right)_{2} \cdot 6 \mathrm{H}_{2} \mathrm{O}$, citric acid, and ammonium carbonate as materials. The decomposition of the precursor complex at $800^{\circ} \mathrm{C}$ for $5 \mathrm{~h}$ led to the formation of $\mathrm{LaNi}_{1-x} \mathrm{Co}_{x} \mathrm{O}_{3}$ powder as confirmed by XRD. Synthesized mixed oxides appeared in both small and large sized flake-like particles. These results confirmed that Co was throughly inserted in $\mathrm{LaNiO}_{3}$ while crystal structure did not change noticeably, but the phases were greatly changed. Moreover, Co contents in the synthesized oxides up to $x=0.5$ improved the surface area.

\section{Acknowledgments}

Financial support of YTU (project No. 27-07-01-07) and technical assistance of Chemical Engineering Department (SEM and XRD), TUBITAK-MAM (BET), and UNIDO-ICHET (BET) are gratefully acknowledged.

\section{References}

[1] J.R. Mawdsley, T.R. Krause, Appl. Catalysis A, General 334, 311 (2008).

[2] S. Cimino, L. Lisi, S. De Rossi, M. Faticanti, P. Porta, Appl. Catalysis B, Environmental 43, 397 (2003).

[3] A. Balasubramanian, N. Karthikeyan, V.V. Giridhar, J. Power Sources 185, 670 (2008).

[4] L. Forni, I. Rossetti, Appl. Catalysis B, Environmental 38, 29 (2002).

[5] N.A. Merino, B.P. Barbero, P. Ruiz, L.E. Cadús, J. Catalysis 240, 245 (2006).

[6] A. Civera, M. Pavese, G. Saracco, V. Specchia, Catalysis Today 83, 199 (2003).

[7] N.A. Merino, B.P. Barbero, P. Grange, L.E. Cadús, J. Catalysis 231, 232 (2005). 